\title{
Distribution of tumor-infiltrating immune cells in glioblastoma
}

\author{
Enrique Orrego1, Carlos A Castaneda*,2,3, Miluska Castillo², Luis A Bernabe², Sandro \\ Casavilca $^{4}$, Arnab Chakravarti ${ }^{5}$, Wei Meng ${ }^{5}$, Pamela Garcia-Corrochano ${ }^{1}$, Maria R \\ Villa-Robles ${ }^{4}$, Rocio Zevallos ${ }^{4}$, Omar Mejia², Pedro Deza ${ }^{1}$, Carolina Belmar-Lopez ${ }^{2}$ \& Luis \\ Ojeda ${ }^{1}$ \\ ${ }^{1}$ Neurosurgery Department, Instituto Nacional de Enfermedades Neoplasicas, Lima, 15038, Peru \\ ${ }^{2}$ Research Department, Instituto Nacional de Enfermedades Neoplasicas, Lima, 15038, Peru \\ ${ }^{3}$ Faculty of Medicine, Universidad Peruana San Juan Bautista, Lima, 15067, Peru \\ ${ }^{4}$ Pathology Department, Instituto Nacional de Enfermedades Neoplasicas, Lima, 15038, Peru \\ ${ }^{5}$ Department of Radiation Oncology, The Ohio State University Comprehensive Cancer Center-Arthur G. James Cancer Hospital, \\ Columbus, OH, 43210, USA \\ *Author for correspondence: Tel.: +511992 157 220; Fax: +511 620 4991; carloscastanedaaltamirano@yahoo.com
}

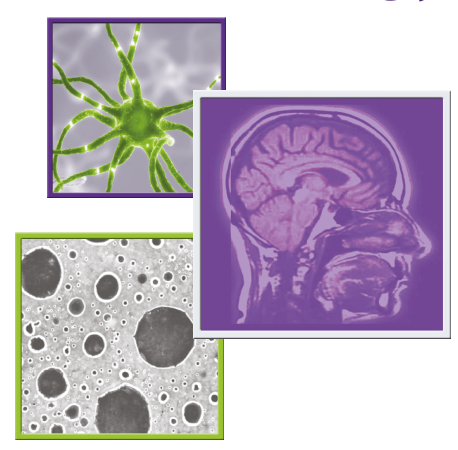

\begin{abstract}
Aim: Evaluation of features related to infiltrating immune cell level in glioblastoma. Methods: Tumorinfiltrating lymphocytes (TILs) through H\&E staining, and TILS (CD3, CD4, CD8 and CD20) and macrophage (CD68 and CD163) levels through immunohistochemistry were evaluated through digital analysis. Results: CD68 (9.1\%), CD163 (2.2\%), CD3 (1.6\%) and CD8 (1.6\%) had the highest density. Higher CD4+ was associated with unmethylated MGMT $(p=0.016)$. Higher $\mathrm{CD}^{+}$was associated with larger tumoral size $(p=0.027)$. Higher $C D 163^{+}$was associated with higher age $(p=0.044)$ and recursive partitioning analysis $=4$. Women $(p<0.05)$, total resection $(p<0.05)$, MGMT-methylation $(p<0.001)$, radiotherapy $(p<0.001)$, chemotherapy $(p<0.001)$ and lower $\mathrm{CD}^{+}(p<0.05)$ were associated with longer overall survival. Conclusion: Macrophages are more frequent than TILs. Some subsets are associated with clinical features.
\end{abstract}

First draft submitted: 16 October 2017; Accepted for publication: 3 May 2018; Published online: 9 October 2018

Keywords: biomarker • glioblastoma • macrophages $\bullet$ MGMT • overall survival • prognosis $\bullet$ tumor-infiltrating lymphocytes

The outcome for most glioblastoma patients is lethal. However, retrospective series have identified a small subset of patients with longer survival, and some clinicopathological features and scores like recursive partitioning analysis (RPA) have demonstrated a prognostic role in glioma patients [1-4].

Glioblastoma patients' survival has been improved under a scheme of postoperative radiation with alkylating chemotherapy and epigenetic silencing of the MGMT as a prognostic biomarker has been associated with increased survival $[1,2,5-10]$. Additional therapies against gliomas, including immunotherapy, are currently under intensive research [11]

Tumor-infiltrating lymphocytes (TILs) have been demonstrated to have a prognostic and predictive role in different malignancies [12-14]. Although the brain is an immunologically isolated organ, the presence of lymphocytes has been documented in gliomas. The role of lymphocytes in the brain has not been fully studied, since previous small studies only investigated certain subpopulations of TILs, depending on the methodologies they used [15-27].

In the present study, we investigated the association between the density of monocyte TILs, CD3, CD4, CD8, CD20 lymphocyte subsets and CD68 and CD163 macrophages over clinicopathological features including MGMT-promoter methylation status and prognosis in 43 glioblastoma cases.

Future $\because \%$ Medicine 


\section{Materials \& methods}

Study population

We examined patient files and pathology reports of the 43 glioblastoma cases who underwent neurosurgical resection at the Department of Neurosurgery at Instituto Nacional de Enfermedades Neoplasicas from January 2008 to July 2013. The histological diagnosis was established and verified by a neuropathologist (S. Casavilca) according to the 2007 WHO classification guidelines.

Tumor size was calculated based on preoperative MRI or CT scan as follows: longest diameter, widest diameter and thickness (number of layers). Clinicopathologic features were summarized in Table 1.

\section{TIL evaluation through H\&E}

Evaluation of TILs was performed, as previously reported, through their distribution (focal, multifocal or diffuse) and intensity (mild, moderate or marked) as well as its presence in perivascular area (absent, mild or definite) through the whole slides of the 43 resected glioblastoma tissues $[15,28]$. The whole evaluation was performed by manual eyeballing by two institute pathologists (S Casavilca and J Sanchez).

\section{Tissue microarrays \& immunohistochemistry}

Tissue microarrays and immunohistochemical staining were performed using the 43 glioma tissue samples as previously described [29]. Briefly, tissue microarrays were constructed with a tissue microarrayer (Quick-Ray Manual Tissue Microarrayer; Unitma Co. Ltd, Seoul, Korea). Each tumor was sampled from representative areas using a 6 $\mathrm{mm}$ punch, yielding composite array blocks comprising a total of eight tissue cores.

Paraffin-embedded specimens were cut into $3 \mu \mathrm{m}$ sections. After deparaffinization with xylene and rehydration, antigen retrieval was performed by microwave treatment in $10 \mathrm{mmol} / \mathrm{l}$ sodium citrate buffer ( $\mathrm{pH}$ 6.0) for 20 min. The endogenous peroxidase was blocked with $3 \% \mathrm{H}_{2} \mathrm{O}_{2}$ in methanol. Nonspecific binding was blocked for 10 min using a protein-blocking buffer. The sections were washed in phosphate-buffered saline. Diluted primary antibodies against CD3 (IS503, Dako, Glostrup, Denmark), CD4 (IS649, Dako), CD8 (IS623, Dako), CD20 (IS604, Dako), CD68 (IS613, Dako) and CD163 (clone MRQ-26; Bio SB, Inc., CA, USA) were applied to the tissue microarray and incubated overnight at $41^{\circ} \mathrm{C}$. For negative controls, the primary antibodies were replaced by normal mouse serum. Human normal tonsil was used as positive control. Samples were then incubated with the horseradish peroxidase labeled secondary antibody in the immunohistochemical kit (DakoKIT-5930, MaxVision, Fu Zhou, PR China) for 30 min at room temperature. Diaminobenzidine was used for color development and hematoxylin as counterstain. Results were visualized and photographed under a light microscope (Olympus BX-63; Olympus Optical Co., Ltd, Tokyo, Japan). The immune cells were digitally quantified using TissueMorph software (Visopharm, Hoerlson, Denmark).

Evaluation was performed by examining each section using at least five different high-power fields ( 40 objective and 10 eyepiece) with the most abundant TIL areas. Percentage of infiltrating immune system cell was calculated by the rate of absolute number of positive staining cells/ total number of cells multiplied by 100 . The whole process was supervised by two institute pathologists (S Casavilca and J Sanchez; Figure 1).

\section{MGMT promoter methylation analysis by methylation-specific PCR}

Methylation-specific PCR was performed to detect MGMT promoter methylation in 31 glioblastomas tumor samples. Briefly, for DNA extraction, six slides (10- $\mu \mathrm{m}$-thick sections) from tissue samples were processed and purified according to the commercial GeneJET FFPE DNA Purification kit (Thermo Scientific, IL, USA). $1 \mu \mathrm{g}$ of the DNA was denatured by $\mathrm{NaOH}$ and modified by sodium bisulfite by EpiJET Bisulfite Conversion Kit (Thermo Scientific, PA, USA), following the manufacturer's directions. Methylation-specific PCR was performed

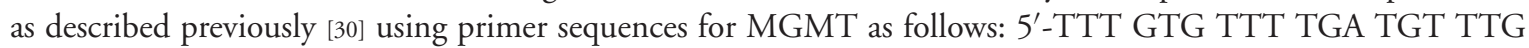
TAG GTT TTT GT-3' (forward) and 5'-AAC TCC ACA CTC TTC CAA AAA CAA AAC A-3' (reverse) and methylated specific primers: 5'-TTT CGA CGT TCG TAG GTT TTC GC-3' (forward) and 5'-GCA CTC TTC CGA AAA CGA AAC G-3' (reverse). In all reactions, a negative control was added, in which the sample was replaced with water. Positive methylation controls: in vitro methylated normal blood lymphocytes in vitro with CpG Methyltransferase. The PCR reaction products were analyzed by electrophoresis on agarose gels (6\%) and stained with a solution of SYBR Safe DNA gel stain (Invitrogen, Life Technologies, CA, USA). The unmethylated or methylated DNA amplicon size was $93 \mathrm{bp}$ and $81 \mathrm{bp}$, respectively. 
Table 1. Clinical features and 3-year overall survival.

\begin{tabular}{|c|c|c|c|}
\hline Features & $n(\%)$ & 3-year OS & $\mathrm{p}$-value \\
\hline \multicolumn{4}{|l|}{ Age (years) } \\
\hline Median (range) & $47 /(8-74)$ & & 0.273 \\
\hline$<48$ & $23(53.5)$ & $11.20 \%$ & \\
\hline$\geq 48$ & $20(46.5)$ & $5.00 \%$ & \\
\hline Gender & & & $<0.05$ \\
\hline Female & $21(48.8)$ & $18.10 \%$ & \\
\hline \multicolumn{3}{|l|}{ Karnofsky (\%) } & 0.7 \\
\hline$\leq 80$ & $15(34.9)$ & $6.70 \%^{\dagger}$ & \\
\hline$>80$ & $28(65.1)$ & $13.10 \%$ & \\
\hline \multicolumn{3}{|l|}{ Seizures } & 0.454 \\
\hline No & $29(67.4)$ & $8.50 \%$ & \\
\hline \multicolumn{3}{|l|}{ Resection } & $<0.05$ \\
\hline Subtotal & $22(51.2)$ & $4.50 \% \S$ & \\
\hline Total & $21(48.8)$ & $17.10 \%$ & \\
\hline \multicolumn{3}{|l|}{ Tumor size (cm) } & 0.739 \\
\hline Median/range & $5(2-7)$ & & \\
\hline$<5$ & $19(44.2)$ & $7.90 \%$ & \\
\hline$\geq 5$ & $24(55.8)$ & $8.30 \%$ & \\
\hline \multicolumn{3}{|l|}{ Pathological subtype } & - \\
\hline Multiform & $31(72.1)$ & $7.00 \%$ & \\
\hline Small cells & $2(4.7)$ & $50.00 \%$ & \\
\hline Mild & $3(7.5)$ & $33.30 \% \mathbb{I}$ & \\
\hline Definite & $6(15.0)$ & $16.70 \%$ & \\
\hline \multicolumn{3}{|l|}{ TIL intensity } & 0.873 \\
\hline Mild & $28(71.8)$ & $4.60 \%$ & \\
\hline Moderate & $10(25.6)$ & $10.00 \%$ & \\
\hline Marked & $1(2.6)$ & $0.00 \%$ & \\
\hline \multicolumn{3}{|l|}{ TIL distribution } & 0.107 \\
\hline Diffuse & $15(38.5)$ & $6.7 \%$ & \\
\hline Focal & $9(23.0)$ & $29.6 \%$ & \\
\hline Multifocal & $15(38.5)$ & $6.70 \%{ }^{\dagger \dagger}$ & \\
\hline \multicolumn{3}{|c|}{ Methylation status of MGMT promoter } & $<0.001$ \\
\hline 1 & $16(51.6)$ & $6.30 \% \#$ & \\
\hline $2-3$ & $15(48.4)$ & $13.30 \%$ & \\
\hline $\begin{array}{l}\text { †OS estimated at } 21 \text { months. } \\
\text { ¥OS estimated at } 25 \text { months. } \\
\text { \&OS estimated at } 18 \text { months. } \\
\text { IOS estimated at } 12 \text { months. } \\
\text { † OS estimated at } 22 \text { months. } \\
\text { \#OS estimated at } 14 \text { months. } \\
\text { ¥¥OS estimated at } 17 \text { months. } \\
\text { OS: Overall survival; RPA: Recursiv }\end{array}$ & analycic· TH & & \\
\hline
\end{tabular}




\begin{tabular}{|c|c|c|c|}
\hline Features & n (\%) & 3-year OS & p-value \\
\hline RPA & & & 0.142 \\
\hline 3 & 15 (34.9) & $18.70 \%$ & \\
\hline 4 & $28(65.1)$ & $3.60 \%$ & \\
\hline Radiotherapy & & & $<0.001$ \\
\hline No & $10(23.3)$ & $10.00 \%$ & \\
\hline Yes & $33(76.7)$ & $7.20 \%$ & \\
\hline Chemotherapy & & & $<0.001$ \\
\hline No & 14 (32.6) & $7.10 \%$ & \\
\hline Yes & $29(67.4)$ & $8.10 \%$ & \\
\hline CD3 & & & 0.295 \\
\hline$<1.6 \%$ & $21(51.2)$ & $11.40 \%$ & \\
\hline$\geq 1.6 \%$ & $20(48.8)$ & $5.00 \%$ & \\
\hline CD4 & & & $<0.05$ \\
\hline$<0.032 \%$ & 19 (48.7) & $15.80 \%$ & \\
\hline$\geq 0.032 \%$ & $20(51.3)$ & $10.00 \% \ddagger \ddagger$ & \\
\hline CD8 & & & 0.059 \\
\hline$<1.6 \%$ & 19 (51.4) & $12.60 \%$ & \\
\hline$\geq 1.6 \%$ & $18(48.6)$ & $5.60 \%$ & \\
\hline CD20 & & & 0.43 \\
\hline$<0.03 \%$ & $19(50)$ & $6.60 \%$ & \\
\hline$\geq 0.03 \%$ & $19(50)$ & $5.30 \%$ & \\
\hline CD68 & & & 0.748 \\
\hline$<9.1 \%$ & $14(50)$ & $7.10 \%$ & \\
\hline$\geq 9.1 \%$ & $14(50)$ & $10.70 \%^{\dagger}$ & \\
\hline CD163 & & & 0.156 \\
\hline$<2.2 \%$ & $18(50)$ & $13.90 \%$ & \\
\hline$\geq 2.2 \%$ & $18(50)$ & $5.60 \%$ & \\
\hline \multicolumn{4}{|c|}{$\begin{array}{l}\text { †OS estimated at } 21 \text { months. } \\
\text { ¥OS estimated at } 25 \text { months. } \\
\text { §OS estimated at } 18 \text { months. } \\
\mathbb{I}_{\text {OS }} \text { estimated at } 12 \text { months. } \\
\text { †OS estimated at } 22 \text { months. } \\
\text { \#OS estimated at } 14 \text { months. } \\
\text { ¥¥OS estimated at } 17 \text { months. } \\
\text { OS: Overall survival; RPA: Recursive partitioning analysis; TLL: Tumor-infiltrating lymphocyte. }\end{array}$} \\
\hline
\end{tabular}

\section{Statistical analysis}

The age, preoperative KPS and tumor size were used as continuous variables whereas all the other covariates as categorical variables. Tumor resection was defined as follows: gross total resection and partial removal. MGMT promoter methylation status was dichotomised into methylation versus unmethylation.

Association between clinicopathological features and immune cell density was performed comparing median percentage of every immune cell: CD3, CD4, CD8, CD20, CD68 and CD163 through chi-square test of independence or Fisher's exact test. Cox regression was used to estimate different levels of hazard ratios according to the number of CD3-, CD4-, CD8-, CD20-, CD68- and CD163-positive cells in glioblastomas and adjusted for age, sex, preoperative Karnofsky performance status (KPS), tumor size, degree of resection and MGMT promoter methylation.

Progression-free survival was defined as the date of diagnosis to the first image confirming recurrence and overall survival (OS) as diagnosis of death or last visit at the clinic. Kaplan-Meier survival analysis was used to determine the distribution of $O S$ and progression-free survival along the time, and the p-values were calculated using log-rank test. Immune cell levels were divided in higher or lower than the median value and a additional score combining the CD3 and CD8 levels regarding their median value (low vs high) was performed for evaluating the impact on OS. 


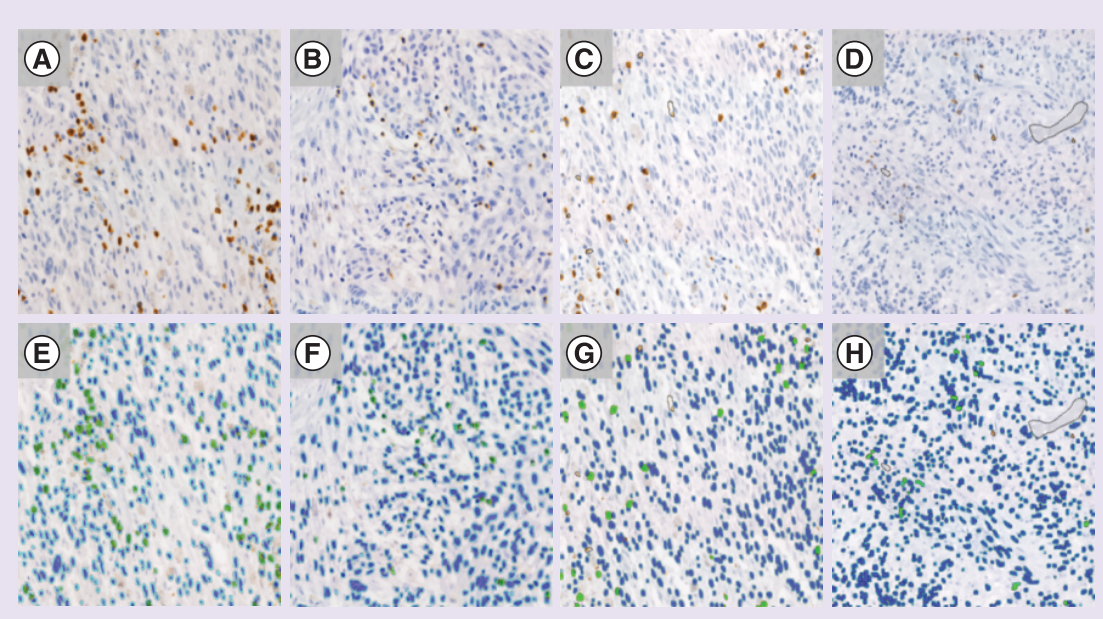

Figure 1. Tumor-infiltrating lyphocytes in glioblastoma. (A, B, C, D) $\mathrm{CD} 3^{+}, \mathrm{CD}^{+}, \mathrm{CD} 8^{+}$and $\mathrm{CD} 20^{+} \mathrm{TIL}$ infiltration in glioblastoma. (E, F, G, H) Digital image analysis of $\mathrm{CD}^{+}, \mathrm{CD}^{+}, \mathrm{CD}^{+}$, and $\mathrm{CD} 20^{+}$staining by TissueMorph software (Visiopharm) showing positive (green) and negative (blue) cells.

Results were performed by statistical softwares R and SPSS 20.0 (IBM, NY, USA). A two-tailed p-value of 0.05 was regarded as significant. Research methodology and information analysis were performed through strengthening the reporting of observational studies in epidemiology endorsement [31].

\section{Results}

\section{Clinicopathological features}

Clinical and pathological features of this glioblastoma cohort $(n=43)$ are shown in Table 1 . The median age was 47 (range 8-74) years and $51.2 \%$ of patients were male. The Karnofsky scores at the diagnosis time were dichotomized at cutoff of 80 (high $>80[65.1 \%]$ ). Seizures were found in 32.6\%. The median tumor size was $5 \mathrm{~cm}$ (range $2-7 \mathrm{~cm})$. Complete resection was performed in $21(48.8 \%)$ patients, both radiotherapy and chemotherapy were administered in $65.1 \%$ patients and only radiotherapy in $11.6 \%$. Median survival after diagnosis was 14 months and $41(95.3 \%)$ patients deceased during follow-up. Female sex $(\mathrm{p}=0.009)$, level of resection $(\mathrm{p}<0.001)$, MGMT promoter methylation $(\mathrm{p}<0.001)$, radiotherapy $(\mathrm{p}<0.001)$, chemotherapy $(\mathrm{p}<0.001)$ and TIL CD4 level $(\mathrm{p}<0.001)$ were significantly associated with OS in the Kaplan-Meier analysis. Age $(\mathrm{p}=0.273)$, Karnofsky score $(\mathrm{p}=0.700), \mathrm{RPA}(\mathrm{p}=0.142)$ and tumor size $(\mathrm{p}=0.739)$ were not associated with OS (Figure 2$)$.

\section{Tumor-infiltrating lymphocyte evaluation through $\mathrm{H}$ \& $\mathrm{E}$}

The TIL intensity was assessed as mild (71.8\%), moderate (25.6\%) or marked (2.6\%). The TIL distribution was classified as focal (23.1\%), multifocal (38.5) or diffuse (38.5\%). Perivascular TIL infiltration was absent (77.5\%), mild $(7.5 \%)$ or definite $(15.0 \%)$. TIL intensity was not associated to age $(\mathrm{p}=0.060)$, sex $(\mathrm{p}=0.798)$, tumor size $(\mathrm{p}=0.956)$, preoperative KPS $(\mathrm{p}=1.000)$, MGMT-promoter methylation $(\mathrm{p}=0.406)$ nor degree of resection $(p=0.648)$. TIL distribution was associated with gender $(p=0.002)$ but not with age $(p=0.097)$, preoperative KPS $(\mathrm{p}=1.000)$, tumor size $(\mathrm{p}=0.916)$, MGMT promoter methylation $(\mathrm{p}=0.775)$ and degree of resection $(p=0.773)$. TIL presence in perivascular area was not associated with age $(p=0.451)$, sex $(p=1.000)$, preoperative KPS $(\mathrm{p}=0.453)$, tumor size $(\mathrm{p}=0.133)$, MGMT promoter methylation $(\mathrm{p}=0.236)$ nor degree of resection $(\mathrm{p}=0.457)$. Neither TIL distribution $(\mathrm{p}=0.107)$, TIL intensity $(\mathrm{p}=0.873)$ nor TIL presence in perivascular area $(\mathrm{p}=0.794)$ was associated with OS (Table 2).

Infiltrating immune system cells evaluation through immunohistochemistry.

The median percentage of CD3, CD4, CD8, CD20, CD68 and CD163 in five high-power fields was 1.6\% (0.1-19.1\%), $0.032 \%$ (0-5.5\%), 1.6\% (0.016-12.1\%), 0.03\% (0-4.7\%), 9.1\% (2.2-42\%) and 2.2\% (0-26.5\%), respectively (Figure 1 ). 

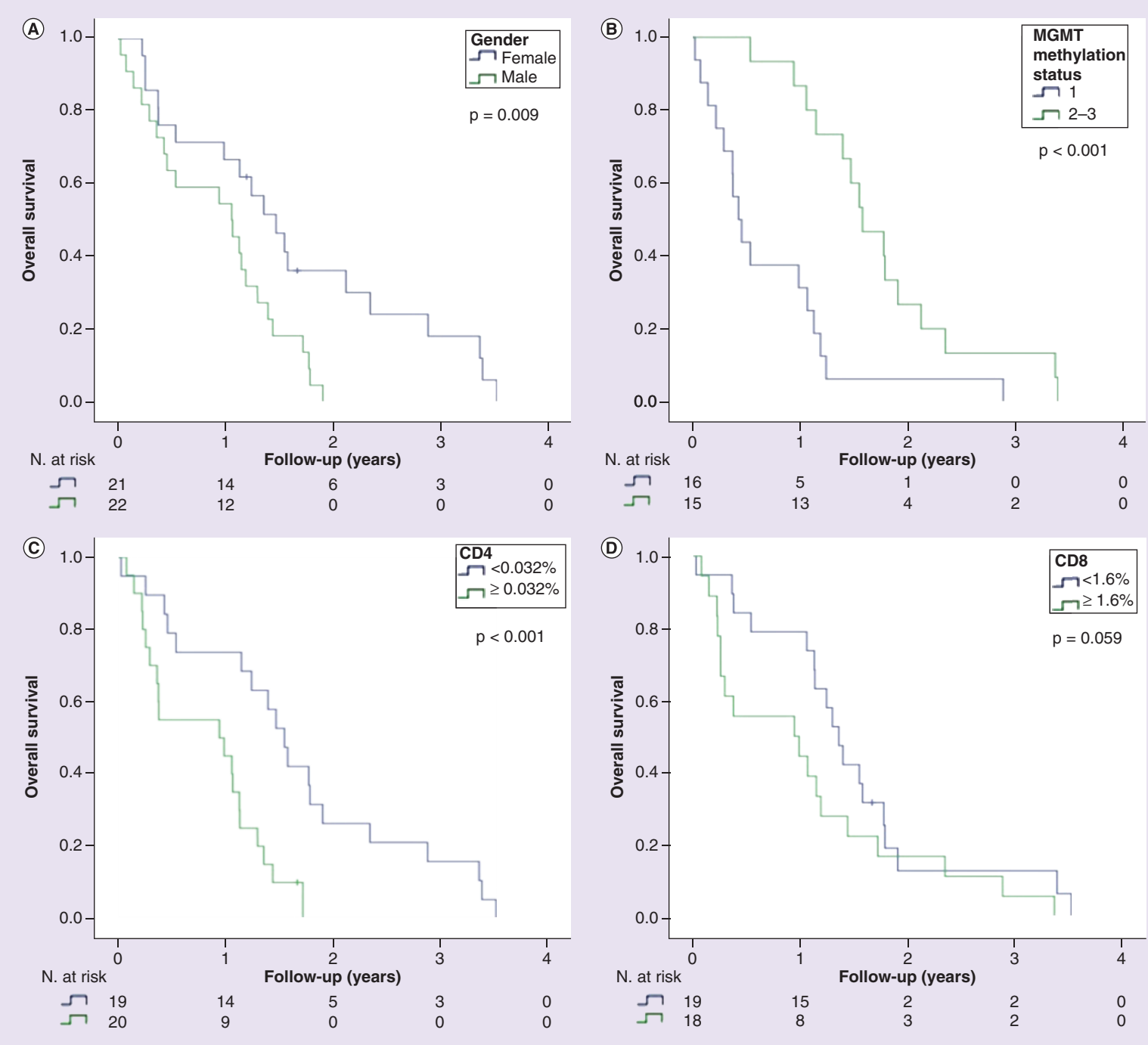

Figure 2. Clinicopathological features associated with survival. Estimated overall survival curve according to gender (A), MGMT methylation status (B), CD4 (C) and CD8 level (D).

Level of CD4 TIL higher than the media was associated with unmethylated MGMT promoter ( $\mathrm{p}<0.05)$, level of CD8 TIL higher than the media was associated with larger tumor size $(\mathrm{p}=0.027)$, level of CD20 TIL higher than the media was associated with presence of perivascular TIL infiltration and level of CD163 macrophages higher than the media was associated with older age and RPA $=4$ (Table 3$)$.

Level of CD3 ( $p=0.295)$, CD8 ( $p=0.059)$, CD20 ( $p=0.430)$, CD68 $(\mathrm{p}=0.748)$ and CD163 ( $\mathrm{p}=0.156)$ were not associated with overall OS. Only CD4 TIL was associated with OS in univariate analysis $(\mathrm{p}<0.05)$ and was kept significant in multivariate analysis $(<0.05)$. Combination of CD3 (high vs low) and CD8 (high vs low) TIL confirmed that those with higher levels of both CD3 and CD8 TIL tend to have the shortest survival $(\mathrm{p}=$ 0.287) (Figure 2).

\section{Discussion}

Different clinicopathological features have been shown to have a significant association with longer survival [1,2,5-10]. Female gender, gross total resection and methylated MGMT status have been confirmed in our institutional cohort as prognostic factors.

In this study, we showed that presence of lymphocytes inside glioblastomas was rare. Therefore, slight and defined perivascular TILs were found in 7.5 and $15 \%$ cases, respectively. Moderate or high intensity was found in $28.2 \%$ 
Table 2. Association of tumor infiltrating lymphocytes intensity, distribution and perivascular state with clinical features.

\begin{tabular}{|c|c|c|c|c|c|c|c|c|c|c|}
\hline \multirow[t]{2}{*}{ Features } & \multicolumn{2}{|c|}{ Total $\mathbf{n}=39^{\dagger}$} & \multirow[t]{2}{*}{ p-value } & \multirow{2}{*}{$\begin{array}{l}\text { Diffuse, } n= \\
15(\%)\end{array}$} & \multicolumn{2}{|c|}{ Total $\mathbf{n}=39 \ddagger$} & \multirow[t]{2}{*}{$p$-value } & \multicolumn{2}{|c|}{ Total $n=40^{\S}$} & \multirow[t]{2}{*}{ p-value } \\
\hline & $\begin{array}{l}\text { Mild, } n=28 \\
(\%)\end{array}$ & $\begin{array}{l}\text { Moderate + } \\
\text { marked, n = } \\
11(\%)\end{array}$ & & & $\begin{array}{l}\text { Focal, } n=9 \\
(\%)\end{array}$ & $\begin{array}{l}\text { Multifocal, n } \\
=15(\%)\end{array}$ & & $\begin{array}{l}\text { Absent, } n= \\
31(\%)\end{array}$ & $\begin{array}{l}\text { Mild + } \\
\text { definite, } n= \\
9(\%)\end{array}$ & \\
\hline Age (years) & & & 0.060 & & & & 0.097 & & & 0.451 \\
\hline $\begin{array}{l}\text { Median } \\
\text { (range) }\end{array}$ & $53(98-74)$ & $44(21-68)$ & & $53(36-73)$ & $37(13-74)$ & $46(8-72)$ & & $51(8-74)$ & 47 (37-73) & \\
\hline$<48$ & 11 (57.9) & $8(42.1)$ & & $4(21.1)$ & $6(31.6)$ & $9(47.4)$ & & $14(70.0)$ & $6(30.0)$ & \\
\hline$\geq 48$ & $17(85.0)$ & $3(15.0)$ & & $11(55.0)$ & $3(15.0)$ & $6(30.0)$ & & $17(85.0)$ & $3(15.0)$ & \\
\hline Gender & & & 0.798 & & & & 0.002 & & & 1.000 \\
\hline Female & 14 (73.7) & $5(26.3)$ & & $10(52.6)$ & $7(36.8)$ & $2(10.5)$ & & $16(80.0)$ & $4(20.0)$ & \\
\hline Male & $14(70.0)$ & $6(30.0)$ & & $5(25.0)$ & $2(10.0)$ & $13(65.0)$ & & $15(75.0)$ & $5(25.0)$ & \\
\hline Karnofsky & & & 1.000 & & & & 1.000 & & & 0.453 \\
\hline$\leq 80$ & $10(71.4)$ & $4(28.6)$ & & $6(42.9)$ & $3(21.4)$ & $5(35.7)$ & & $12(85.7)$ & $2(14.3)$ & \\
\hline$>80$ & $18(72.0)$ & $7(28.0)$ & & $9(36.0)$ & $6(24.0)$ & $10(40.0)$ & & $19(73.1)$ & 7 (26.9) & \\
\hline Resection & & & 0.648 & & & & 0.773 & & & 0.457 \\
\hline Subtotal & $13(68.4)$ & $6(31.6)$ & & $8(42.1)$ & $5(26.3)$ & $6(31.6)$ & & $16(84.2)$ & $3(15.8)$ & \\
\hline Total & $15(75.0)$ & $5(25.0)$ & & $7(35.0)$ & $4(20.0)$ & $9(45.0)$ & & $15(71.4)$ & $6(28.6)$ & \\
\hline $\begin{array}{l}\text { Promotor } \\
\text { MGMT }\end{array}$ & & & 0.406 & & & & 0.775 & & & 0.236 \\
\hline 1 & $13(81.2)$ & $3(18.8)$ & & $7(43.8)$ & $3(18.8)$ & $6(37.5)$ & & $13(81.2)$ & $3(18.8)$ & \\
\hline $2 / 3$ & $8(61.5)$ & $5(38.5)$ & & $6(46.2)$ & $1(7.7)$ & $6(46.2)$ & & $8(57.1)$ & $6(42.9)$ & \\
\hline $\begin{array}{l}\text { Tumor size } \\
(\mathrm{cm})\end{array}$ & & & 0.956 & & & & 0.916 & & & 0.133 \\
\hline $\begin{array}{l}\text { Median } \\
\text { (range) }\end{array}$ & $5(2-7)$ & $5.1(3-7)$ & & $5(3.3-7)$ & $4(2-5.3)$ & $5(3.2-7)$ & & $4.7(2-7)$ & $5.9(3.3-6.3)$ & \\
\hline$<5 \mathrm{~cm}$ & $13(72.2)$ & $5(27.8)$ & & $6(33.3)$ & $5(27.8)$ & $7(38.9)$ & & $17(89.5)$ & $2(10.5)$ & \\
\hline$\geq 5 \mathrm{~cm}$ & $15(71.4)$ & $6(28.6)$ & & $9(42.9)$ & $4(19.0)$ & $8(38.1)$ & & $14(66.7)$ & 7 (33.3) & \\
\hline
\end{tabular}

$\dagger$ Four cases do not specify TIL intensity category.

$\ddagger$ Four cases do not specify TIL distribution category.

$\S$ Three cases do not specify perivascular state.

TIL: Tumor-infiltrating lymphocyte.

and diffuse TIL distribution was found in 38.5\%. However, no association with clinicopathological features was found.

Bertrand and Mannen et al. were credited as the first to describe TIL presence in gliomas and found that 63 out of $172(36.6 \%)$ astrocytoma cases harbored perivascular lymphocytes, however, most of these cases were weak and were not associated with a better outcome [24].

The follow-up studies with less than 100 gliomas cases confirmed that $28-31 \%$ gliomas cases harbored perivascular infiltrating lymphocytes, although no correlation between the presence of TILs and the clinical prognosis was found [18,25,32-34].

TIL subpopulations contained more T-lymphocyte subtype (median CD3: 1.6\%) than B-lymphocyte subtype (median CD20: 0.03\%), and almost all T-lymphocytes were CD8+. Macrophages were more frequent than lymphocytes (median CD68: 9.1\%) and activated macrophages represented almost a third of them (median CD163: 2.2\%) in our glioblastoma patient cohort. In our study, necrosis was ubiquitously present in glioblastoma, and necrotic tissues have been previously described as highly infiltrated by macrophages. This association could explain the relatively high density of macrophages in our glioblastoma series.

Compared with other reported malignancies, the densities of immune cell subpopulation in our study were low, which can be explained by the blood-brain barrier and specific local microenvironmental features. These low densities makes it necessary to select only areas with TIL conglomerates for subpopulation analysis [13,14].

The low CD3 TILs were associated with larger tumor size, the low CD4 TILs were associated with methylated MGMT promoter status and low CD8 TILs had a trend to be associated with methylated MGMT promoter status in our univariate analysis (and CD4 in multivariate analysis). Consistent with the association between methylated 


\begin{tabular}{|c|c|c|c|c|c|c|}
\hline Features & $\mathrm{CD} 3(n=41)$ & CD4 $(n=39)$ & CD8 $(n=37)$ & $\operatorname{CD} 20(n=38)$ & $\mathrm{CD} 68(n=28)$ & CD163 $(n=36)$ \\
\hline Median (range) & $1.59(0.1-19.1)$ & $0.032(0-5.5)$ & $1.6(0.016-12.1)$ & $0.03(0-4.7)$ & $9.06(2.2-42)$ & $2.22(0-26.5)$ \\
\hline Age (years) & $\mathrm{n}=41 \mathrm{NS}$ & $\mathrm{n}=39 \mathrm{NS}$ & $\mathrm{n}=37 \mathrm{NS}$ & $\mathrm{n}=38 \mathrm{NS}$ & $\mathrm{n}=28 \mathrm{NS}$ & $\mathrm{n}=36^{\dagger}$ \\
\hline$-<48$ & $1.59 /(0.1-15.6)$ & $0 /(0-3.1)$ & $1.62 /(0-11.4)$ & $0.06 /(0-3.5)$ & $9.56 /(3.1-42)$ & $1.44 /(0-15.6)$ \\
\hline$-\geq 48$ & $1.69 /(0.2-19.1)$ & $0.04 /(0-5.5)$ & $1.59 /(0.1-12.1)$ & $0.02 /(0-4.7)$ & $7.58 /(2.2-37)$ & $3.54 /(0-26.5)$ \\
\hline Gender & $n=41 \mathrm{NS}$ & $n=39$ NS & $n=39 \mathrm{NS}$ & $\mathrm{n}=38 \mathrm{NS}$ & $\mathrm{n}=28 \mathrm{NS}$ & $\mathrm{n}=36 \mathrm{NS}$ \\
\hline - Female & $1.21 /(0.1-15.6)$ & $0.01 /(0-5.5)$ & $1.59 /(0-10.2)$ & $0.03 /(0-0.4)$ & $5.94 /(2.2-37)$ & $1.45 /(0-26.5)$ \\
\hline - Male & $2.19 /(0.1-19.1)$ & $0.14 /(0-3.1)$ & $1.64 /(0.1-12.1)$ & $0.03 /(0-4.7)$ & $11.07 /(4-42)$ & $3.51 /(0-16.3)$ \\
\hline Karnofsky & $\mathrm{n}=41 \mathrm{NS}$ & $\mathrm{n}=39 \mathrm{NS}$ & $\mathrm{n}=37 \mathrm{NS}$ & $\mathrm{n}=38 \mathrm{NS}$ & $\mathrm{n}=28 \mathrm{NS}$ & $\mathrm{n}=36 \mathrm{NS}$ \\
\hline$-\leq 80$ & $1.14 /(0.1-12.8)$ & $0.03 /(0-3.1)$ & $0.98 /(0.1-9)$ & $0.03 /(0-3.5)$ & $7.95 /(2.2-37)$ & $3.6 /(0-13)$ \\
\hline$->80$ & $2.08 /(0.1-19.1)$ & $0.03 /(0-5.5)$ & $1.88 /(0-12.1)$ & $0.04 /(0-4.7)$ & $10.3 /(3.1-42)$ & $1.51 /(0-26.5)$ \\
\hline Resection & $n=41 \mathrm{NS}$ & $\mathrm{n}=39 \mathrm{NS}$ & $\mathrm{n}=37 \mathrm{NS}$ & $\mathrm{n}=38 \mathrm{NS}$ & $\mathrm{n}=28 \mathrm{NS}$ & $\mathrm{n}=36 \mathrm{NS}$ \\
\hline Subtotal & $2.08 /(0.1-19.1)$ & $0.09 /(0-5.5)$ & $1.84 /(0.1-11.9)$ & $0.04 /(0-4.7)$ & $9.48 /(4.3-42)$ & $3.54 /(0-15.6)$ \\
\hline Total & $1.21 /(0.1-15.6)$ & $0 /(0-1.9)$ & $0.53 /(0-12.1)$ & $0.02 /(0-0.4)$ & $8.63 /(2.2-31.2)$ & $1.58 /(0-26.5)$ \\
\hline Tumor size $(\mathrm{cm})$ & $\mathrm{n}=41 \mathrm{NS}$ & $\mathrm{n}=39 \mathrm{NS}$ & $\mathrm{n}=37^{\dagger}$ & $\mathrm{n}=38 \mathrm{NS}$ & $\mathrm{n}=28 \mathrm{NS}$ & $\mathrm{n}=36 \mathrm{NS}$ \\
\hline$<5$ & $1.12 /(0.1-19.1)$ & $0.04 /(0-1.1)$ & $0.98 /(0.1-11.9)$ & $0.02 /(0-4.7)$ & $8.63 /(2.2-37)$ & $1.01 /(0-13)$ \\
\hline$\geq 5$ & $2.96 /(0.1-15.6)$ & $0.03 /(0-5.5)$ & $2.19 /(0-12.1)$ & $0.04 /(0-1)$ & $10.3 /(2.9-42)$ & $2.69 /(0-26.5)$ \\
\hline $\begin{array}{l}\text { Methylation status of } \\
\text { MGMT promoter }\end{array}$ & $\mathrm{n}=30 \mathrm{NS}$ & $\mathrm{n}=28^{\dagger}$ & $\mathrm{n}=26 \mathrm{NS}$ & $\mathrm{n}=28 \mathrm{NS}$ & $\mathrm{n}=20 \mathrm{NS}$ & $\mathrm{n}=25 \mathrm{NS}$ \\
\hline-1 & $3.27 /(0.1-13.4)$ & $0.04 /(0-5.5)$ & $1.88 /(0.2-12.1)$ & $0.1 /(0-4.7)$ & $11.46 /(2.2-42)$ & $4.63 /(0.2-15.6)$ \\
\hline$-2 / 3$ & $1.2 /(0.1-19.1)$ & $0 /(0-1.5)$ & $0.32 /(0.1-11.9)$ & $0.01 /(0-0.4)$ & $8.63 /(3.1-31.2)$ & $1.37 /(0-26.5)$ \\
\hline RPA & $\mathrm{n}=41 \mathrm{NS}$ & $\mathrm{n}=39 \mathrm{NS}$ & $\mathrm{n}=37 \mathrm{NS}$ & $\mathrm{n}=38 \mathrm{NS}$ & $\mathrm{n}=28 \mathrm{NS}$ & $\mathrm{n}=36^{\dagger}$ \\
\hline-3 & $1.52 /(0.1-15.6)$ & $0 /(0-1.6)$ & $2.05 /(0-11.4)$ & $0.07 /(0-0.4)$ & $10.3 /(3.1-42)$ & $0.35 /(0-15.6)$ \\
\hline-4 & $1.59 /(0.1-19.1)$ & $0.09 /(0-5.5)$ & $1.59 /(0.1-12.1)$ & $0.03 /(0-4.7)$ & $7.95 /(2.2-37)$ & $3.6 /(0-26.5)$ \\
\hline Perivascular & $\mathrm{n}=38 \mathrm{NS}$ & $\mathrm{n}=36 \mathrm{NS}$ & $\mathrm{n}=34 \mathrm{NS}$ & $\mathrm{n}=35^{\dagger}$ & $\mathrm{n}=26 \mathrm{NS}$ & $\mathrm{n}=33 \mathrm{NS}$ \\
\hline - Absence & $1.12 /(0.1-19.1)$ & $0.03 /(0-5.5)$ & $0.98 /(0-12.1)$ & $0.02 /(0-1)$ & $7.77 /(2.2-37)$ & $2.22 /(0-16.3)$ \\
\hline - Presence & $4.63 /(0.4-15.6)$ & $0.27 /(0-1.6)$ & $3.15 /(0.1-10.2)$ & $0.35 /(0-4.7)$ & $17.34 /(3.9-42)$ & $2.72 /(0-26.5)$ \\
\hline
\end{tabular}

MGMT and longer survival, we found that lower levels of CD4 TILs were predicted and lower levels of CD8 also had a trend of predicting better patient outcomes in our study.

Farmer $e t$ al. demonstrated that $\mathrm{CD}^{+}$and $\mathrm{CD} 4^{+}$TILs consisted of 41 and $42 \%$ of TILs in nine high-grade gliomas, respectively [35].

Hitchcock and Morris assessed the presence of TILs through immunohistochemistry in five low-grade and 15 high-grade astrocytomas and found that both low- and high-grade tumors harbored an average of 4.5-4.2\%, 9.6-9.4\% and $26-36 \%$ of $\mathrm{CD}^{+}, \mathrm{CD}^{+}$and macrophages, respectively [36].

Kuppner $e t$ al. evaluated TILs through immunohistochemistry in seven glioblastoma specimens and found scarce lymphocytes. Absence of slight, moderate and markedly intense of CD3 staining were found in four specimens, one and two specimens, respectively. Absence of rare and moderate intense of CD4 expression was found in five and two specimens, respectively. Absence of rare, moderate and markedly intense CD8 expression was found in four, two and one specimen, respectively [37].

El Andaloussi and Lesniak studied TILs in ten glioblastomas and six control brain specimens. The analysis of single cell tumor suspensions by Flow cytometry revealed that lymphocytes represented approximately $17 \%$ (12$21 \%$ ) of cells whereas less than $1 \%$ was found in control brain samples. CD3 ${ }^{+}$TIL were $25 \%$ and approximately $6 \%$ were $\mathrm{CD}_{4}{ }^{+} \mathrm{CD} 25^{+}$and displayed a tumor suppressor function in vitro. Of the $\mathrm{CD} 4{ }^{+}$cells in TILs, 55\% expressed FoxP3, a Treg-specific protein critical to regulatory T-cell development and function [19].

Hussain et al. evaluated 50 glioblastoma tumors and found that the predominant immune cells were microglia and macrophages. They also demonstrated that infiltrating $\mathrm{CD} 8^{+}$TIL were phenotypically $\mathrm{CD} 25^{-}$and most $\mathrm{CD}^{+}{ }^{+}$TIL were $\mathrm{CD} 25^{+} \mathrm{FOXP}^{+}{ }^{[38] \text {. }}$ 
Consistent with our results, Kim et al. evaluated 67 glioblastomas cases and found that CD8 were more frequent than CD4 (6.8 vs 1.5 cells in average). They found a relationship between high levels of CD8 TIL and longer survival, but not for $\mathrm{CD}^{+}$TIL [22].

Sayour et al. evaluated 57 glioblastoma cases and found that the CD8 TIL absolute count was more than three-times than the $\mathrm{CD}^{+}$, and FoxP3 TIL represented less than a third of CD4 ${ }^{+}$TIL. Absolute numbers of TIL did not predict outcome, but the increased ratio of CD3 and CD8 over FoxP3 TIL was positively correlated with survival outcomes [39].

Yang et al. evaluated 108 glioblastoma cases and found that higher CD8 ${ }^{+}$TIL cells are associated with longer survival (intermediate or extensive T-cell infiltrates in long-term survivors vs short-term survivors was 38 vs $20 \%$, respectively; $\mathrm{p}<0.006$ ) [40].

Madkouri et al. evaluated 186 glioblastoma tumors and found that CD163 macrophage infiltrates were highly and homogeneously stained and $\mathrm{CD}^{+}$TIL infiltrates were less frequent and preferentially located in perivascular area. Higher $\mathrm{CD}^{+}$TIL infiltrates were associated with good prognosis [41].

Differences in the effect of CD4 ${ }^{+}$TIL presence in previous glioblastoma studies and our results are probably the result of their double-edged immunological sword. On one hand, CD4 helper T cells perform critical roles in the recruitment, activation and regulation of many facets of the adaptive immune response including activation of CD8 TIL cells [42]. Therefore, the presence of CD4 helper T cells has been associated with better survival in different malignancies including breast cancer. On the other hand, CD4 Tregs can dampen anti-tumor immunity and promote tumor progression [43]. Tregs are unfavorable prognostic markers in patients with breast cancer [44], hepatocellular carcinoma [45] and pancreatic cancer [46]. Our findings of an inverse association between CD8 TIL density and survival coincide with the trend of inverse association with MGMT methylation status. This could indicate that tumor epigenetic alterations can modulate anticancer immune activity.

In conclusion, tumor infiltrating immune cells are not common in glioblastomas and demonstrate that immune factors like the density of infiltrating lymphocyte subsets can affect the outcome of glioblastoma patients with current standard therapies.

\section{Future perspective}

Many strategies are currently being developed for modulating host immune activity against different malignancies; however, they are active only in some patients, carry toxicities and are expensive. We expect that more effective immunomodulators will be developed in the near future and will demonstrate anticancer activity in some glioblastoma cases. However, it will be necessary to identify those patients who will obtain the best benefit from these agents, and a signature combining levels of immune cells could be a predictive and prognosis biomarker. An objective methodology to quantify infiltrating immune cell like that used in this research is expected to be standard in the close future.

\section{Summary points}

- Median survival in glioblastoma is short.

- Clinical features can identify glioblastoma patients with longer survival.

- Density of immune cell inside glioblastoma lesion is low.

- Most frequent immune cell in glioblastoma is macrophages.

- Density of CD8 and CD163 was associated to aggressiveness features and density of CD4 to survival. 


\section{Ethical conduct of research}

The conduct of this survey was approved The Institutional Review Board of INEN (\#051-2016-CRP-DI-DICON/INEN), and written informed consent was obtained from each glioma tissue donor who agreed to the use of the tumor tissue and clinical data for future research when possible.

\section{Open access}

This work is licensed under the Attribution-NonCommercial-NoDerivatives 4.0 Unported License. To view a copy of this license, visit http://creativecommons.org/licenses/by-nc-nd/4.0/

\section{References}

Papers of special note have been highlighted as: $\bullet$ of interest; $\bullet \bullet$ of considerable interest

1. Hegi ME, Diserens AC, Godard S et al. Clinical trial substantiates the predictive value of O-6-methylguanine-DNA methyltransferase promoter methylation in glioblastoma patients treated with temozolomide. Clin. Cancer Res. 10(6), 1871-1874 (2004).

2. Hegi ME, Diserens AC, Gorlia T et al. MGMT gene silencing and benefit from temozolomide in glioblastoma. N. Engl. J. Med. 352(10), 997-1003 (2005).

3. Stupp R, Hegi ME, Mason WP et al. Effects of radiotherapy with concomitant and adjuvant temozolomide versus radiotherapy alone on survival in glioblastoma in a randomised Phase III study: 5-year analysis of the EORTC-NCIC trial. Lancet Oncol. 10(5), 459-466 (2009).

4. Li J, Wang M, Won M et al. Validation and simplification of the Radiation Therapy Oncology Group recursive partitioning analysis classification for glioblastoma. Int. J. Radiat. Oncol. Biol. Phys. 81(3), 623-630 (2011).

5. Felsberg J, Thon N, Eigenbrod S et al. Promoter methylation and expression of MGMT and the DNA mismatch repair genes MLH1, MSH2, MSH6 and PMS2 in paired primary and recurrent glioblastomas. Int. J. Cancer 129(3), 659-670 (2011).

6. Chinot OL, Wick W, Mason W et al. Bevacizumab plus radiotherapy-temozolomide for newly diagnosed glioblastoma. N. Engl. J. Med. 370(8), 709-722 (2014).

7. Gilbert MR, Dignam JJ, Armstrong TS et al. A randomized trial of bevacizumab for newly diagnosed glioblastoma. N. Engl. J. Med. 370(8), 699-708 (2014).

8. Gilbert MR, Wang M, Aldape KD et al. Dose-dense temozolomide for newly diagnosed glioblastoma: a randomized Phase III clinical trial. J. Clin. Oncol. 31(32), 4085-4091 (2013).

9. Wick W, Platten M, Meisner C et al. Temozolomide chemotherapy alone versus radiotherapy alone for malignant astrocytoma in the elderly: the NOA-08 randomised, Phase 3 trial. Lancet Oncol. 13(7), 707-715 (2012).

10. Malmstrom A, Gronberg BH, Marosi C et al. Temozolomide versus standard 6-week radiotherapy versus hypofractionated radiotherapy in patients older than 60 years with glioblastoma: the Nordic randomised, Phase III trial. Lancet Oncol. 13(9), 916-926 (2012).

11. Polivka J Jr., Polivka J, Holubec L et al. Advances in experimental targeted therapy and immunotherapy for patients with glioblastoma multiforme. Anticancer Res. 37(1), 21-33 (2017).

12. Salgado R, Denkert C, Demaria $S$ et al. The evaluation of tumor-infiltrating lymphocytes (TILs) in breast cancer: recommendations by an International TILs Working Group 2014. Ann. Oncol. 26(2), 259-271 (2014).

13. Sato $\mathrm{E}$, Olson $\mathrm{SH}, \mathrm{Ahn} \mathrm{J}$ et al. Intraepithelial $\mathrm{CD} 8+$ tumor-infiltrating lymphocytes and a high $\mathrm{CD} 8^{+} /$regulatory $\mathrm{T}$ cell ratio are associated with favorable prognosis in ovarian cancer. Proc. Natl Acad. Sci. USA 102(51), 18538-18543 (2005).

14. Galon J, Costes A, Sanchez-Cabo F et al. Type, density and location of immune cells within human colorectal tumors predict clinical outcome. Science 313(5795), 1960-1964 (2006).

15. Palma L, Di Lorenzo N, Guidetti B. Lymphocytic infiltrates in primary glioblastomas and recidivous gliomas. Incidence, fate and relevance to prognosis in 228 operated cases. J. Neurosurg. 49(6), 854-861 (1978).

16. Brooks WH, Markesbery WR, Gupta GD, Roszman TL. Relationship of lymphocyte invasion and survival of brain tumor patients. Ann. Neurol. 4(3), 219-224 (1978).

17. Smyth MJ, Dunn GP, Schreiber RD. Cancer immunosurveillance and immunoediting: the roles of immunity in suppressing tumor development and shaping tumor immunogenicity. Adv. Immunol. 90, 1-50 (2006).

18. von Hanwehr RI, Hofman FM, Taylor CR, Apuzzo ML. Mononuclear lymphoid populations infiltrating the microenvironment of primary CNS tumors. Characterization of cell subsets with monoclonal antibodies. J. Neurosurg. 60(6), 1138-1147 (1984).

19. El Andaloussi A, Lesniak MS. An increase in CD4+ CD25 + FOXP3 + regulatory T cells in tumor-infiltrating lymphocytes of human glioblastoma multiforme. Neuro Oncol. 8(3), 234-243 (2006).

20. Heimberger AB, Abou-Ghazal M, Reina-Ortiz C et al. Incidence and prognostic impact of FoxP3 + regulatory T cells in human gliomas. Clin. Cancer Res. 14(16), 5166-5172 (2008).

21. Lohr J, Ratliff T, Huppertz A et al. Effector T-cell infiltration positively impacts survival of glioblastoma patients and is impaired by tumor-derived TGF-beta. Clin. Cancer Res. 17(13), 4296-4308 (2011). 
22. Kim YH, Jung TY, Jung S et al. Tumour-infiltrating T-cell subpopulations in glioblastomas. Br. J. Neurosurg. 26(1), 21-27 (2012).

-• Evaluation of 67 glioblastomas found that CD8 were more frequent than CD4 and were associated with longer survival.

23. Yue Q, Zhang X, Ye HX et al. The prognostic value of Foxp3 + tumor-infiltrating lymphocytes in patients with glioblastoma. J. Neurooncol. 116(2), 251-259 (2014).

24. Bertrand I, Mannen H. Etudes des reactions vasculaires dans les astrocytomes. Rev. Neurol. 102, 3-19 (1960).

- It is the first to describe tumor-infiltrating lymphocyte presence in gliomas and to describe that $36.6 \%$ of astrocytomas harbored perivascular lymphocytes (weak).

25. Ridley A, Cavanagh JB. Lymphocytic infiltration in gliomas: evidence of possible host resistance. Brain 94(1), 117-124 (1971).

26. Takeuchi J, Barnard R. Perivascular lymphocytic cuffing in astrocytomas. Acta Neuropathol. 35(3), 265 (1976).

27. Yu JS, Lee PK, Ehtesham M, Samoto K, Black KL, Wheeler CJ. Intratumoral T-cell subset ratios and Fas ligand expression on brain tumor endothelium. J. Neurooncol. 64(1-2), 55-61 (2003).

28. Berghoff AS, Kiesel B, Widhalm G et al. Programmed death ligand 1 expression and tumor-infiltrating lymphocytes in glioblastoma. Neuro Oncol. 17(8), 1064-1075 (2015).

29. Han S, Zhang C, Li Q et al. Tumour-infiltrating CD4 ( + ) and CD8 (+ ) lymphocytes as predictors of clinical outcome in glioma. Br. J. Cancer 110(10), 2560-2568 (2014).

30. Esteller M, Hamilton SR, Burger PC, Baylin SB, Herman JG. Inactivation of the DNA repair gene O6-methylguanine-DNA methyltransferase by promoter hypermethylation is a common event in primary human neoplasia. Cancer Res. 59(4), 793-797 (1999).

31. von Elm E, Altman DG, Egger M et al. The Strengthening the Reporting of Observational Studies in Epidemiology (STROBE) Statement: guidelines for reporting observational studies. Int. J. Surg. 12(12), 1495-1499 (2014).

32. Dunn GP, Dunn IF, Curry WT. Focus on TILs: prognostic significance of tumor infiltrating lymphocytes in human glioma. Cancer Immun. 7, 12 (2007).

33. Sawamura Y, Hosokawa M, Kuppner MC et al. Antitumor activity and surface phenotypes of human glioma-infiltrating lymphocytes after in vitro expansion in the presence of interleukin 2. Cancer Res. 49(7), 1843-1849 (1989).

34. Takeuchi J, Barnard RO. Perivascular lymphocytic cuffing in astrocytomas. Acta Neuropathol. 35(3), 265-271 (1976).

35. Farmer JP, Antel JP, Freedman M, Cashman NR, Rode H, Villemure JG. Characterization of lymphoid cells isolated from human gliomas. J. Neurosurg. 71(4), 528-533 (1989).

36. Hitchcock ER, Morris CS. Mononuclear cell infiltration in central portions of human astrocytomas. J. Neurosurg. 68(3), 432-437 (1988).

37. Kuppner MC, Hamou MF, de Tribolet N. Immunohistological and functional analyses of lymphoid infiltrates in human glioblastomas. Cancer Res. 48(23), 6926-6932 (1988).

38. Hussain SF, Yang D, Suki D, Aldape K, Grimm E, Heimberger AB. The role of human glioma-infiltrating microglia/macrophages in mediating antitumor immune responses. Neuro Oncol. 8(3), 261-279 (2006).

39. Sayour EJ, McLendon P, McLendon R et al. Increased proportion of FoxP3 + regulatory T cells in tumor infiltrating lymphocytes is associated with tumor recurrence and reduced survival in patients with glioblastoma. Cancer Immunol. Immunother. 64(4), 419-427 (2015).

40. Yang I, Tihan T, Han SJ et al. CD8 ${ }^{+}$T-cell infiltrate in newly diagnosed glioblastoma is associated with long-term survival. J. Clin. Neurosci. 17(11), 1381-1385 (2010).

-. Evaluation of 108 glioblastoma cases that found that higher $\mathrm{CD8}^{+}$tumor-infiltrating lymphocytes cells are associated with longer survival.

41. Madkouri R, Kaderbhai CG, Bertaut A et al. Immune classifications with cytotoxic CD8 ${ }^{+}$and Th17 infiltrates are predictors of clinical prognosis in glioblastoma. Oncoimmunology 6(6), e1321186 (2017).

- Evaluation of 186 glioblastoma tumors that found that CD163 macrophage cell infiltrates were frequent in the perivascular area.

42. Bos R, Marquardt KL, Cheung J, Sherman LA. Functional differences between low- and high-affinity CD8 $\left({ }^{+}\right) \mathrm{T}$ cells in the tumor environment. Oncoimmunology 1(8), 1239-1247 (2012).

43. Zamarron BF, Chen W. Dual roles of immune cells and their factors in cancer development and progression. Int. J. Biol. Sci. 7(5), 651-658 (2011).

44. Gobert M, Treilleux I, Bendriss-Vermare N et al. Regulatory T cells recruited through CCL22/CCR4 are selectively activated in lymphoid infiltrates surrounding primary breast tumors and lead to an adverse clinical outcome. Cancer Res. 69(5), 2000-2009 (2009).

45. Gao Q, Qiu SJ, Fan J et al. Intratumoral balance of regulatory and cytotoxic $\mathrm{T}$ cells is associated with prognosis of hepatocellular carcinoma after resection. J. Clin. Oncol. 25(18), 2586-2593 (2007).

46. Hiraoka N, Onozato K, Kosuge T, Hirohashi S. Prevalence of FOXP3 ${ }^{+}$regulatory $\mathrm{T}$ cells increases during the progression of pancreatic ductal adenocarcinoma and its premalignant lesions. Clin. Cancer Res. 12(18), 5423-5434 (2006). 
Research Article Orrego, Castaneda, Castillo et al. 